\title{
Relevance of the time interval between surgery and adjuvant radio (chemo) therapy in HPV-negative and advanced head and neck carcinoma of unknown primary (CUP)
}

Matthias Balk ${ }^{1 *}$, Robin Rupp ${ }^{1}$, Konstantin Mantsopoulos ${ }^{1}$, Moritz Allner ${ }^{1}$, Philipp Grundtner ${ }^{1}$, SK Mueller ${ }^{1}$, Maximilian Traxdorf ${ }^{1}$, Markus Eckstein ${ }^{2}$, Stefan Speer ${ }^{3}$, Sabine Semrau ${ }^{3}$, Rainer Fietkau ${ }^{3}$, Heinrich Iro ${ }^{1}$, Markus Hecht ${ }^{3}$ and Antoniu-Oreste Gostian ${ }^{1}$

\begin{abstract}
Introduction: In contrast to head and neck squamous cell carcinoma (HNSCC), the effect of treatment duration in HNSCC-CUP has not been thoroughly investigated. Thus, this study aimed to assess the impact of the time interval between surgery and adjuvant therapy on the oncologic outcome, in particular the 5-year overall survival rate (OS), in advanced stage, HPV-negative CUPS at a tertiary referral hospital. 5-year disease specific survival rate (DSS) and progression free survival rate (PFS) are defined as secondary objectives.

Material and methods: Between January 1st, 2007, and March 31st, 2020 a total of 131 patients with CUP were treated. Out of these, 59 patients with a confirmed negative p16 analysis were referred to a so-called CUPpanendoscopy with simultaneous unilateral neck dissection followed by adjuvant therapy. The cut-off between tumor removal and delivery of adjuvant therapy was set at the median, i.e. patients receiving adjuvant therapy below or above the median time interval.
\end{abstract}

Results: Depending on the median time interval of 55 days (d) (95\% Cl 51.42-84.52), 30 patients received adjuvant therapy within $55 \mathrm{~d}$ (mean $41.69 \mathrm{~d}, \mathrm{SD}=9.03$ ) after surgery in contrast to 29 patients at least after $55 \mathrm{~d}$ (mean 73.21 $\mathrm{d}, \mathrm{SD}=19.16)$. All patients involved in the study were diagnosed in advanced tumor stages UICC III $(n=4 ; 6.8 \%)$, IVA $(n=27 ; 45.8 \%)$ and IVB $(n=28 ; 47.5 \%)$.

Every patient was treated with curative neck dissection. Adjuvant chemo (immune) radiation was performed in 55 patients (93.2\%), 4 patients (6.8\%) underwent adjuvant radiation only. The mean follow-up time was 43.6 months ( $\mathrm{SD}=36.7$ months).

\footnotetext{
* Correspondence: matthias.balk@uk-erlangen.de

1 Department of Otolaryngology, Head \& Neck Surgery, University Hospital

Erlangen, Friedrich-Alexander University Erlangen-Nuremberg, 91054

Erlangen, Germany

Full list of author information is available at the end of the article
}

(c) The Author(s). 2021 Open Access This article is licensed under a Creative Commons Attribution 4.0 International License, which permits use, sharing, adaptation, distribution and reproduction in any medium or format, as long as you give appropriate credit to the original author(s) and the source, provide a link to the Creative Commons licence, and indicate if changes were made. The images or other third party material in this article are included in the article's Creative Commons licence, unless indicated otherwise in a credit line to the material. If material is not included in the article's Creative Commons licence and your intended use is not permitted by statutory regulation or exceeds the permitted use, you will need to obtain permission directly from the copyright holder. To view a copy of this licence, visit http://creativecommons.org/licenses/by/4.0/ The Creative Commons Public Domain Dedication waiver (http://creativecommons.org/publicdomain/zero/1.0/) applies to the data made available in this article, unless otherwise stated in a credit line to the data. 


\begin{abstract}
The 5-year OS rate for all patients involved was $71 \%$ (95\% Cl 0.55-0.86). For those patients receiving adjuvant therapy within $55 \mathrm{~d}(77,95 \% \mathrm{Cl} 0.48-1.06)$ the OS rate was higher, yet not significantly different from those with delayed treatment $\left(64,95 \% \mathrm{Cl} 0.42-0.80 ; X^{2}{ }_{(1)}=1.16, p=0.281\right)$.

Regarding all patients, the 5 -year DSS rate was $86 \%(95 \% \mathrm{Cl} 0.75-0.96)$. Patients submitted to adjuvant treatment in less than $55 \mathrm{~d}$ the DSS rate was $95 \%$ (95\% Cl 0.89-1.01) compared to patients submitted to adjuvant treatment equal or later than $55 \mathrm{~d}\left(76 \%\left(95 \% \mathrm{Cl} 0.57-0.95 ; \mathrm{X}^{2}{ }_{(1)}=2.32, p=0.128\right)\right.$. The 5 -year PFS rate of the entire cohort was $72 \%(95 \% \mathrm{Cl} 0.59-0.85)$. In the group $<55 \mathrm{~d}$ the PFS rate was $78 \%(95 \% \mathrm{Cl} 0.63-0.94)$ and thus not significantly different from $65 \%$ (95\% Cl 0.45-0.85) of the group $\geq 55 \mathrm{~d} ;\left(X^{2}{ }_{(1)}=0.29, p=0.589\right)$.

Conclusions: The results presented suggest that the oncologic outcome of patients with advanced, HPV-negative CUP of the head and neck was not significantly affected by a prolonged period between surgery and adjuvant therapy. Nevertheless, oncologic outcome tends to be superior for early adjuvant therapy.
\end{abstract}

Keywords: CUP-syndrome, Delayed adjuvant therapy, Advanced head and neck cancer, Neck dissection

\section{Introduction}

In about $2-5 \%$ of head and neck cancer patients with cervical lymph node metastases no primary tumor location can be found [1-3], leading to the diagnosis "cancer of unknown primary" (CUP).

Although various entities have been reported, the most common histology is squamous cell carcinoma accounting for $53-77 \%$ of the cases [4]. In this regard, the differentiation between human papilloma virus (HPV)positive and -negative CUP-syndromes has been shown to influence treatment outcome with favorable outcomes for HPV-positive CUP [5]. However, HPV prevalence differs substantially from 22 and $91 \%$ between studies [2, 5-8]. Information on the 5-year survival rates varies impressively between 29 and $82 \%$ according to the relevant literature [8-12].

For early-stage disease treatment options include ipsilateral selective neck dissection followed by radiation therapy or chemoradiation or primary radiation / chemoradiation therapy that allow for comparable survival rates of up to $61.2 \%$ after 5 years [13].

For patients with a single positive cervical node without extranodal extension treated by a comprehensive neck dissection defined as dissection of levels II-IV including at least 18 identified lymph nodes adjuvant radiotherapy may be avoided if the compliance allows for a thorough surveillance of the patient [14]. In contrast, locally advanced disease, i.e. UICC tumor stage III and IV, require a combined approach consisting of neck dissection followed by adjuvant radiation / chemoradiation [15-19].

In accordance with the general recommendation for head and neck squamous cell carcinoma (HNSCC) by Chen et al., adjuvant therapy for CUP is also recommended to be implemented within 6 weeks following ablative surgery [20]. Apart from the necessity for adjuvant therapy for advanced stage disease, there exist no valid analyses on the time range between surgery and adjuvant therapy for CUPs.
This study focusses solely on HPV negative CUPs and assesses as primary objective the impact of the time range between surgery and adjuvant therapy on the oncologic outcome, in particular the 5-year overall survival rate, at a tertiary referral hospital. The recurrence of disease, i.e. regional metastases and distant metastases, the 5 -year disease specific survival rate and the 5-year progression free survival rate were defined as secondary objectives.

\section{Patients and methods}

This retrospective cohort study was conducted at a single tertiary referral and academic cancer center. It was carried out according to the Declaration of Helsinki and approved by the local Ethics Committee (approval number $428 \_20$ Bc).

All patients diagnosed with a p16 negative CUPsyndrome between January 1st, 2007, and March 31st, 2020, were included. The following inclusion criteria were applied: surgical treatment at our institution, histologically confirmed squamous cell carcinoma, complete medical and surgical record available, confirmed negative p16-status. The association with HPV was confirmed by overexpression of the surrogate marker p16INK4a.

The following exclusion criteria were applied: histological types other than squamous cell carcinoma, detection of the primary cancer, positive or unknown p16status or discontinued treatment.

Smoking was defined as current smokers with a smoking history of at least more than 10 pack years, Alcohol consumption was defined as reported daily alcohol intake.

The treatment process for CUPs involved firstly a "notouch"-panendoscopy followed either by a core needle biopsy or node picking of the suspicious lymph node. Subsequently, a positron emission tomography (PET) was performed. If there was no evidence of the primary 
cancer, the PET was followed by a so-called CUPpanendoscopy that included a curettage of the nasopharynx, bilateral tonsillectomy and multiple biopsies of the tongue base. Simultaneously, the respective neck dissection was performed on the side of the previously diagnosed malignant lymph node. In case of contralateral suspicious lymph nodes a bilateral neck dissection was performed.

Based on the median time interval between upfront neck dissection and implementation of adjuvant therapy, the patients were divided into two groups resulting in one group with less than the median (early treatment group) and one group with above the median (delayed treatment group) until start of the adjuvant therapy.

Adjuvant treatment consisted of either radiation therapy or chemoradiation. Indications for chemoradiation were extranodal extension and more than one affected lymph node [14].

Neck dissection was classified according to Robbins et al. where selective neck dissection denotes preservation of one or more groups of lymph nodes, modified radical neck dissection denotes preservation of one or more non-lymphatic structures and radical neck dissection denotes removal of the spinal accessory nerve, the sternocleidomastoid muscle and the internal jugular vein besides the lymph node groups [21]. Furthermore the Lymph Node Ratio (LNR) was determined and was defined as the number of positive lymph nodes divided by the total number of lymph nodes removed [22, 23].

Radiation techniques included 3D conformal radiation therapy, intensity-modulated radiation therapy (IMRT), or volumetric modulated arc therapy (VMAT). The dosage of radiation was 64Gray (Gy) in the area of the affected lymph node and 56Gy in the ipsilateral neck. The contralateral neck and possible primary sites (i.e. tonsils bilaterally, tongue base and hypopharynx) received 50Gy. A dose of 70Gy was delivered to the nasopharynx. Treatment was delivered either in single doses of 2.0Gy sequentially in shrinking field technique or as simultaneous integrated boost using single doses of up to 2.3Gy up to biologically equivalent cumulative doses. The standard approach for concomitant chemotherapy was two cycles of 5-Fluorouracil $\left(800 \mathrm{mg} / \mathrm{m}^{2}\right.$ body surface area (BSA) continuous infusion $\mathrm{d} 1-5)$ in combination with Cisplatin (100 mg/m² BSA) or Carboplatin (AUC 5) splitted to $3-5$ days.

\section{Study objectives}

Recurrence of disease was defined as regional tumor recurrence or distant metastasis. The primary objective was the 5-year overall survival rate and was calculated from the date of the neck dissection to the date of death from any cause. The secondary objectives such as the 5year disease specific survival rate was calculated from the date of the neck dissection to the date of death from the disease. Additionally, the 5-year progression free survival rate was calculated from the date of the neck dissection to the date of progression of the disease. Patients that were still alive at the time of the follow-up cut-off were censored. Follow-up consisted of a clinical examination with a thorough ultrasound performed by an ENT specialist covering both sides of the neck every 6 weeks in the first year after the disease, every three months in the second and third year and every six months in the fourth and fifth year after finishing the treatment of the disease. A computed tomography scan of the neck and thorax was performed once a year. The tumor stage was determined according to the 8th version of the UICC [24].

\section{Statistical analysis}

Continuous variables were tested for normal distribution using the Kolmogoroff-Smirnov test and each variable's histogram. Consequently, normally distributed parameters are presented as mean \pm 1 standard deviation (SD) and compared via independent T-Tests. In case of nonnormally distributed variables, the median $[1 . ; 3$. Quartile] is additionally presented, and group comparisons were performed with the Mann-Whitney- $U$-test.

Categorical variables are presented as absolute and relative values $(\mathrm{N} / \%)$ and compared with the Chi-Square-Test or with the Exact Fischer-Test, whatever applicable. Survival rates were created by using the Kaplan-Meier-Method and compared by the Log-Rank-Test. Overall-, disease-specific and progression free survival values are presented as Kaplan-Meier estimates and 95\% confidential intervals (CI). Effect sizes for $\mathrm{chi}^{2}$-tests are reported as phi in case of nominal variables with 2 levels. A phi of 0.1 displays a small effect, 0.3 a medium, and 0.5 a strong effect [25].

A $p$-value of less than 0.05 was considered statistically significant. Statistical analysis was performed using IBM SPSS Statistics, version 26.0 (IBM Corp., Armonk, NY, USA).

\section{Results \\ Patient characteristics}

Between January 1st, 2007, and March 31st, 2020 a total of 131 patients were treated with a CUP-syndrome at our Department. Out of these, 59 patients with a confirmed negative p16 status were referred to a so-called CUP-panendoscopy with simultaneous neck dissection followed by adjuvant therapy. The entire patient cohort averaged 60.76 years $(\mathrm{yrs})(\mathrm{SD}=10.42 \mathrm{yrs})$ and included 49 male patients $(83.1 \%)$.

The neck dissection was performed in 23 patients on the left side (39\%), in 32 patients on the right side $(54.2 \%)$ and in 4 patients simultaneously on both sides (6.8\%). 
Both groups did not differ significantly with respect to gender $\left(\mathrm{X}_{(1)}^{2}=0.57, p=0.451\right)$, age $\left(\mathrm{t}_{(57)}=1.97, p=\right.$ $0.054)$, nodal stage $\left(\mathrm{X}_{(4)}^{2}=2.99, p=0.559\right)$, UICC stage $\left(\mathrm{X}_{(2)}^{2}=1.16, \mathrm{p}=0.559\right.$, there was no stage I or II), extranodal extension $\left(\mathrm{X}_{(1)}^{2}=0.61, p=0.436\right)$, noxious agents (smoking $\mathrm{X}_{(1)}^{2}=0.14, p=0.711$, alcohol $\mathrm{X}_{(1)}^{2}=3.78, p=$ $0.151)$ and the ASA-Score $\left(\mathrm{X}_{(2)}^{2} 0.35, p=0.841\right)$. The most common reasons for delayed initiation of adjuvant therapy were organizational reasons, patient indecision, and in few cases delayed wound healing.

All patients were diagnosed in advanced tumor stages UICC III $(n=4 ; 6.8 \%)$, IVA $(n=15 ; 25.4 \%)$ and IVB $(n=$ $40 ; 67.8 \%$ ) with complete absence of early tumor stages I and II (Table 2). Furthermore, 40 out of 59 patients (67.8\%) had a pN3b nodal stage. Patients' characteristics are presented in Table 2 revealing no significant differences between both patient groups.

\section{Treatment characteristics}

All patients were treated with curative neck dissection of whom 33 patients $(55.9 \%)$ received a selective neck dissection, 10 patients (17\%) a modified radical neck dissection and 16 patients (27.1\%) underwent a radical neck dissection. Adjuvant chemo (immune) radiation was performed in 55 patients (93.2\%) whereas 4 patients (6.8\%) underwent adjuvant radiation only. The mean follow-up time was 43.59 months ( $\mathrm{SD}=36.71$ months). The median duration from curative tumor removal to the beginning of adjuvant therapy was $55 \mathrm{~d}$ (95\% CI 51.42-84.52).

Accordingly, 30 patients received adjuvant therapy within less than $55 \mathrm{~d}$ after surgery in contrast to 29 patients that received adjuvant therapy after at least $55 \mathrm{~d}$.

The early treatment group started with adjuvant therapy following ablative surgery on average after $41.69 \mathrm{~d}$ $(\mathrm{SD}=9.03)$ in contrast to the delayed adjuvant treatment

Table 1 Patients' characteristics

\begin{tabular}{|c|c|c|c|c|}
\hline & $\begin{array}{l}\text { All patients } \\
(n=59)\end{array}$ & $\begin{array}{l}\text { Early treatment } \\
\text { group }(n=30)\end{array}$ & $\begin{array}{l}\text { Delayed treatment } \\
\text { group }(n=29)\end{array}$ & Statistical comparison \\
\hline \multicolumn{5}{|l|}{ Gender (n, \%) } \\
\hline Male & 49 (83.0\%) & $26(86.7 \%)$ & $23(79.3 \%)$ & \multirow[t]{2}{*}{$X_{(1)}^{2}=0.57, p=0.451$} \\
\hline Female & $10(17.0 \%)$ & $4(13.3 \%)$ & $6(20.7 \%)$ & \\
\hline Age (mean years $\pm S D$ ) & $60.76 \pm 10.42$ & $58.43 \pm 9.39$ & $63.17 \pm 11.03$ & $t_{(57)}=1.97, p=0.054$ \\
\hline \multicolumn{5}{|l|}{ Nodal stage $(n, \%)$} \\
\hline $\mathrm{pN} 1$ & $5(8.5 \%)$ & $4(13.3 \%)$ & $1(3.5 \%)$ & \multirow{6}{*}{$X_{(3)}^{2}=2.20, p=0.533$} \\
\hline $\mathrm{pN} 2 \mathrm{a}$ & $5(8.5 \%)$ & $3(10.0 \%)$ & $2(6.9 \%)$ & \\
\hline $\mathrm{pN} 2 \mathrm{~b}$ & $9(15.2 \%)$ & $4(13.3 \%)$ & $5(17.2 \%)$ & \\
\hline $\mathrm{pN} 2 \mathrm{C}$ & $0(0 \%)$ & $0(0 \%)$ & $0(0 \%)$ & \\
\hline pN3a & $0(0 \%)$ & $0(0 \%)$ & $0(0 \%)$ & \\
\hline $\mathrm{pN} 3 \mathrm{~b}$ & $40(67.8 \%)$ & 19 (63.4\%) & $21(72.4 \%)$ & \\
\hline \multicolumn{5}{|l|}{ UICC stage $(n, \%)$} \\
\hline III & $4(6.8 \%)$ & $3(10.0 \%)$ & $1(3.5 \%)$ & \multirow[t]{3}{*}{$X_{(2)}^{2}=1.15, p=0.563$} \\
\hline IVA & $15(25.4 \%)$ & $8(26.7 \%)$ & $7(24.1 \%)$ & \\
\hline IVB & $40(67.8 \%)$ & 19 (63.3\%) & $21(72.4 \%)$ & \\
\hline \multicolumn{5}{|c|}{ Extranodal extension (n, \%) } \\
\hline Yes & $42(71,19 \%)$ & $20(66.7 \%)$ & $22(75.9 \%)$ & \multirow[t]{2}{*}{$X_{(1)}^{2}=0.61, p=0.436$} \\
\hline No & $17(28.81 \%)$ & $10(33.3 \%)$ & 7 (24.1\%) & \\
\hline \multicolumn{5}{|l|}{ Noxious agents } \\
\hline Smoking & $42(71.2 \%)$ & $22(73.3 \%)$ & $20(69.0 \%)$ & $X_{(1)}^{2}=0.14, p=0.711$ \\
\hline Alcohol & $41(69.5 \%)$ & 19 (63.3\%) & $22(75.9 \%)$ & $X_{(1)}^{2}=3.78, p=0.151$ \\
\hline \multicolumn{5}{|l|}{ ASA-Score } \\
\hline 1 & $5(8.5 \%)$ & $3(10.0 \%)$ & $2(6.9 \%)$ & \multirow[t]{3}{*}{$X_{(2)}^{2} 0.35, p=0.841$} \\
\hline 2 & 47 (79.7\%) & $23(76.7 \%)$ & $24(82.7 \%)$ & \\
\hline 3 & 7 (11.8\%) & $4(13.3 \%)$ & $3(10.3 \%)$ & \\
\hline
\end{tabular}

Abbreviations: Early treatment group = adjuvant treatment was implemented in less than $55 \mathrm{~d}$ after surgery; Delayed treatment group $=$ adjuvant treatment was implemented within or later than $55 \mathrm{~d}$ following surgery; SD standard deviation; UICC International Union Against Cancer; ASA American Society of Anesthesiologists 
Table 2 Treatment characteristics

\begin{tabular}{|c|c|c|c|c|}
\hline & $\begin{array}{l}\text { All patients } \\
(n=59)\end{array}$ & $\begin{array}{l}\text { Early treatment } \\
\text { group }(n=30)\end{array}$ & $\begin{array}{l}\text { Delayed treatment } \\
\text { group }(n=29)\end{array}$ & Statistical comparison \\
\hline \multicolumn{5}{|l|}{ Time span } \\
\hline Neck Dissection - Adjuvant Therapy (mean $d \pm S D$ ) & $57.45 \pm 21.75$ & $41.69 \pm 9.03$ & $73.21 \pm 19.16$ & $\mathrm{t}_{(56)}=8.01, p<0.001$ \\
\hline \multicolumn{5}{|l|}{ Surgical treatment modality (n, \%) } \\
\hline Selective Neck Dissection & $33(55.9 \%)$ & $19(63.3 \%)$ & $14(48.3 \%)$ & \\
\hline Modified Radical Neck Dissection & $10(17.0 \%)$ & $5(16.7 \%)$ & $5(17.2 \%)$ & $X_{(2)}^{2}=1.74, p=0.419$ \\
\hline Radical Neck Dissection & $16(27.12 \%)$ & $6(20.0 \%)$ & $10(34.5 \%)$ & \\
\hline \multicolumn{5}{|l|}{ Adjuvant treatment modality (n, \%) } \\
\hline Radiation therapy & $4(6.8 \%)$ & $2(6.7 \%)$ & $2(6.9 \%)$ & Fisher's Z: $p>0.999$ \\
\hline Chemoradiation therapy & $55(93.2 \%)$ & $28(93.3 \%)$ & $27(93.1 \%)$ & \\
\hline Radiation dose in Gy (mean \pm SD) & $69.84 \pm 8.19$ & $70.41 \pm 8.88$ & $69.25 \pm 7.54$ & $Z=0.49, p=0.621$ \\
\hline \multicolumn{5}{|l|}{ Chemotherapy (n, \%) } \\
\hline Cisplatin/ Carboplatin+ 5-FU & $31(56.4 \%)$ & $17(60.7 \%)$ & $14(51.8 \%)$ & $X_{(1)}^{2}=0.44, p=0.508$ \\
\hline Other & $24(43.6 \%)$ & $11(39.3 \%)$ & $13(48.2 \%)$ & \\
\hline Number of removed lymph nodes & $21.95 \pm 10.70$ & $21.30 \pm 10.96$ & $22.62 \pm 10.61$ & $\mathrm{t}_{(57)}=0.47, p=0.639$ \\
\hline Lymph Node Ratio (LNR; mean \pm SD) & $0.25 \pm 0.43$ & $0.31 \pm 0.57$ & $0.18 \pm 0.21$ & $Z=1.11, p=0.268$ \\
\hline
\end{tabular}

Abbreviations: Early treatment group = adjuvant treatment was implemented in less than $55 \mathrm{~d}$ after surgery; Delayed treatment group $=$ adjuvant treatment was implemented within or later than 55 d following surgery; SD standard deviation; Gy Gray; 5-FU 5-Fluorouracil

starting on average after $73.21 \mathrm{~d}\left(\mathrm{SD}=19.16 ; \mathrm{t}_{(56)}=8.01\right.$, $p<0.001)$.

Treatment modalities were similarly distributed between both treatment groups with respect to the surgical treatment modality (selective neck dissection, modified radical neck dissection, radical neck dissection; $\mathrm{X}_{(2)}^{2}=$ $1.74, p=0.419)$, the number of removed lymph nodes $\left(t_{(57)}=0.47, p=0.639\right)$, regarding the Lymph Node Ratio $(\mathrm{Z}=1.11, p=0.268)$, the adjuvant treatment modality (radiation therapy, chemoradiation therapy; Fisher's $\mathrm{Z}$ : $p>0.999)$, the radiation dose in Gray $(\mathrm{Z}=0.49, p=$
$0.621)$ and the chemotherapy regimen $\left(\mathrm{X}_{(1)}^{2}=0.44, p=\right.$ 0.508 ; Tables 1, 2 and 3). One patient refused chemotherapy and was treated with radiation therapy only. Tables 1, 2 and 3 display the patient' characteristics and applied treatment modalities.

\section{Oncologic outcomes}

Regarding all patients, the 5-year overall survival rate was $71 \%$ (95\% CI $0.55-0.86)$. Patients receiving adjuvant therapy within $55 \mathrm{~d}(77,95 \% \mathrm{CI} 0.48-1.06)$ had a higher, yet not significantly different overall survival rate

Table 3 Oncological outcomes

\begin{tabular}{|c|c|c|c|c|}
\hline & $\begin{array}{l}\text { All patients } \\
(n=59)\end{array}$ & $\begin{array}{l}\text { Early treatment } \\
\text { group }(n=30)\end{array}$ & $\begin{array}{l}\text { Delayed treatment } \\
\text { group }(n=29)\end{array}$ & $\begin{array}{l}\text { Statistical } \\
\text { comparison }\end{array}$ \\
\hline \multicolumn{5}{|l|}{ Recurrence of disease: } \\
\hline Local \& Regional metastases & $5(8.5 \%)$ & $3(10.0 \%)$ & $2(6.9 \%)$ & \multirow[t]{2}{*}{$X^{2}{ }_{(1)}=1.57, p=0.692$} \\
\hline Distant metastases & $11(18.6 \%)$ & $5(16.7 \%)$ & $6(20.7 \%)$ & \\
\hline \multicolumn{5}{|l|}{ 5-year OS rate } \\
\hline Events (death) & $11(18.6 \%)$ & $4(16.7 \%)$ & $7(24.1 \%)$ & \multirow[t]{2}{*}{$X^{2}{ }_{(1)}=1.16, p=0.281^{*}$} \\
\hline KM Estimate (95\%-CI) & $0.71[0.55 ; 0.86]$ & $0.77[0.48 ; 1.06]$ & $0.64[0.42 ; 0.80]$ & \\
\hline \multicolumn{5}{|l|}{ 5-year DSS rate } \\
\hline Events (death) & $6(10.2 \%)$ & $1(3.3 \%)$ & $5(17.2 \%)$ & \multirow[t]{2}{*}{$X^{2}{ }_{(1)}=2.32, p=0.128^{*}$} \\
\hline KM Estimate (95\%-CI) & $0.86[0.75 ; 0.96]$ & $0.95[0.89 ; 1.01]$ & $0.76[0.57 ; 0.95]$ & \\
\hline \multicolumn{5}{|l|}{ 5-year PFS rate } \\
\hline Events (death) & $14(23.7 \%)$ & $6(20.0 \%)$ & $8(27.6 \%)$ & \multirow[t]{2}{*}{$X^{2}{ }_{(1)}=0.29, p=0.589^{*}$} \\
\hline KM Estimate (95\%-Cl) & $0.72[0.59 ; 0.85]$ & $0.78[0.63 ; 0.94]$ & $0.65[0.45 ; 0.85]$ & \\
\hline
\end{tabular}

Abbreviations: Early treatment group = adjuvant treatment was implemented in less than $55 \mathrm{~d}$ after surgery; Delayed treatment group = adjuvant treatment was implemented within or later than $55 \mathrm{~d}$ following surgery; OS overall survival; DSS disease-specific survival; PFS progression-free survival; KM Kaplan-Meier. *Calculated with the Log-Rank-Test 
compared to those with delayed treatment $(64,95 \% \mathrm{CI}$ $0.42-0.80 ; \mathrm{X}_{(1)}^{2}=1.16, p=0.281$; Fig. 1$)$.

The 5-year disease-specific survival rate of all patients was $86 \%$ (95\% CI 0.75-0.96). For patients receiving adjuvant treatment in less than $55 \mathrm{~d}$ it was 95\% (95\% CI 0.89-1.01) compared to patients receiving adjuvant treatment equal or later than $55 \mathrm{~d}$ (76\% (95\% CI $0.57-$ $0.95 ; \mathrm{X}_{(1)}^{2}=2.32, p=0.128$; Fig. 2).

The 5-year progression-free survival rate of the entire cohort was $72 \%$ (95\% CI $0.59-0.85)$. In the early treatment group, it was 78\% (95\% CI 0.63-0.94) and thus not significantly different from $65 \%$ (95\% CI $0.45-0.85)$ of the delayed treatment group $\left(\mathrm{X}_{(1)}^{2}=0.29, p=0.589\right.$; Fig. 3).

In total, 5 patients $(8.5 \%)$ experienced a regional recurrence, i.e. on the ipsilateral neck side, averaging 36.6 months $(\mathrm{SD}=53.78)$ after adjuvant chemoradiation. Three patients $(10 \%)$ of the early treatment group developed a regional recurrence averaging 51.33 months $(\mathrm{SD}=68.99)$ after adjuvant therapy. Similarly, 2 out of 30 patients $(6.9 \%)$ of the delayed treatment group developed a regional recurrence after 14.5 months $(\mathrm{SD}=$ 20.51) (Fisher's Z: $p>0.999$, phi $=-0.056$ ).

Out of all surveyed patients, 11 patients (18.6\%) presented with distant metastasis averaging 12.0 months
$(\mathrm{SD}=9.22)$ during follow up. Five out of 30 patients (16.7\%) of the early treatment group developed distant metastasis averaging 9.2 months $(\mathrm{SD}=4.97)$ after adjuvant therapy and 6 out of 29 patients $(20.7 \%)$ of the delayed treatment group developed distant metastasis averaging 14.33 months $(\mathrm{SD}=11.66)$ after adjuvant therapy $\left(\mathrm{X}_{(1)}^{2}=1.57, p=0.692\right.$, phi $\left.=0.052\right)$.

Patients with extranodal extensions were significantly more likely to have distant metastases compared with those who did not have extranodal extensions $(11 / 42$ $(26.2 \%)$ vs. $0 / 17(0 \%)$, Fisher's $\mathrm{z}: \mathrm{p}=0,024$, $\mathrm{phi}=0,305)$. There was no difference regarding regional recurrence (ENE+: 4/42 (9.5\%) vs. ENE-:1/17 (5,9\%), Fisher's z: $p>$ 0.999, phi $=0,059$ ).

\section{Discussion}

The results of this study indicate that a prolonged time between surgery and the implementation of subsequent adjuvant therapy for advanced staged head and neck CUP at the cut-off of 55 days did not significantly compromise the 5-year overall survival rate, the 5-year disease-specific survival rate and the 5-year progressionfree survival rate. However, early treatment tended to be superior. Additionally, the rate for regional recurrence and distant metastases was not affected distinctly by the

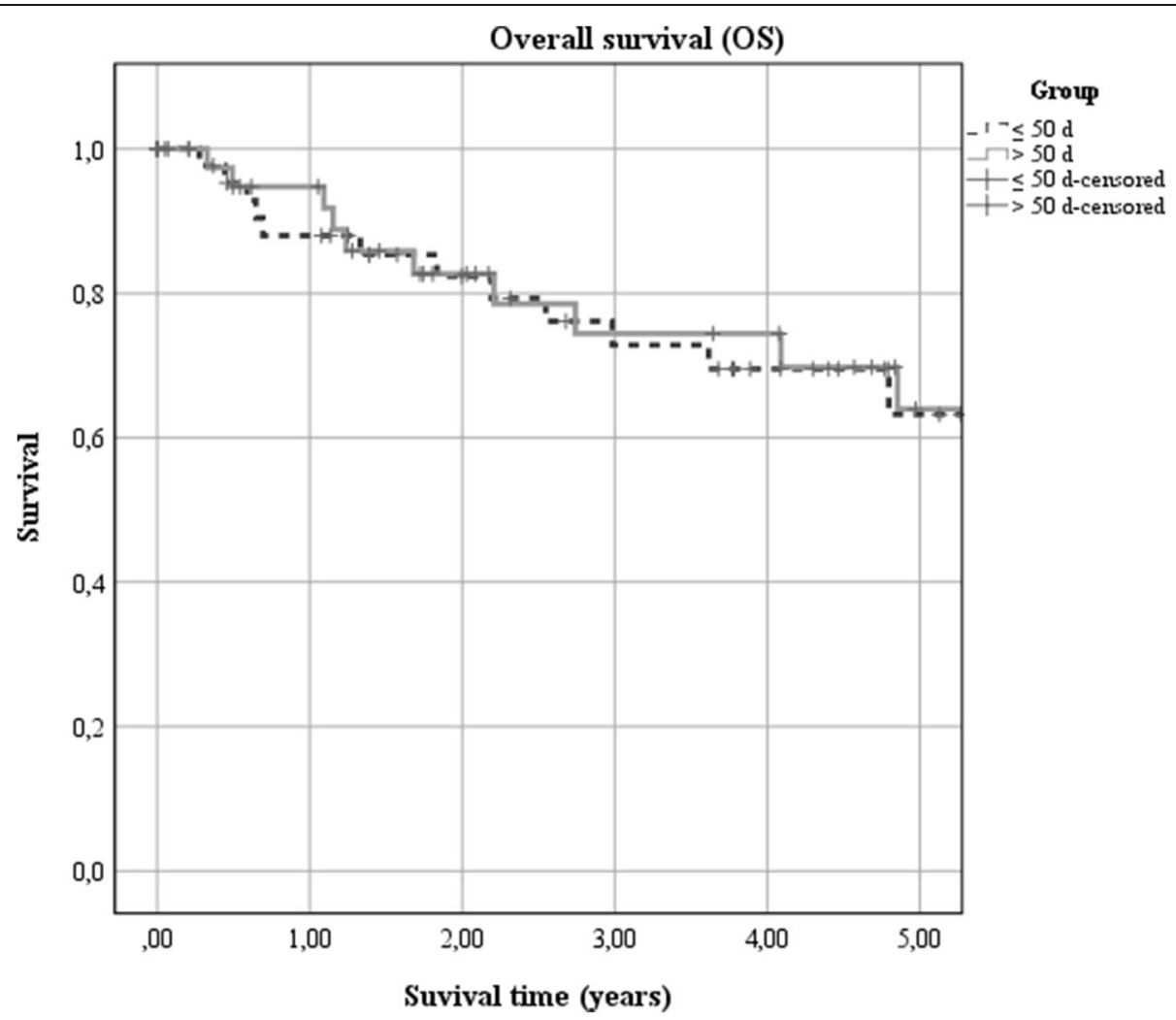

Fig. 1 Association of time span from surgery to adjuvant therapy with overall survival. Kaplan-Meier estimates of overall survival according to the implementation of adjuvant therapy within $(<55 d)$ and later than $55 d(\geq 50 d)$ after surgery $\left(X^{2}{ }_{(1)}=1.16, p=0.281\right)$ 


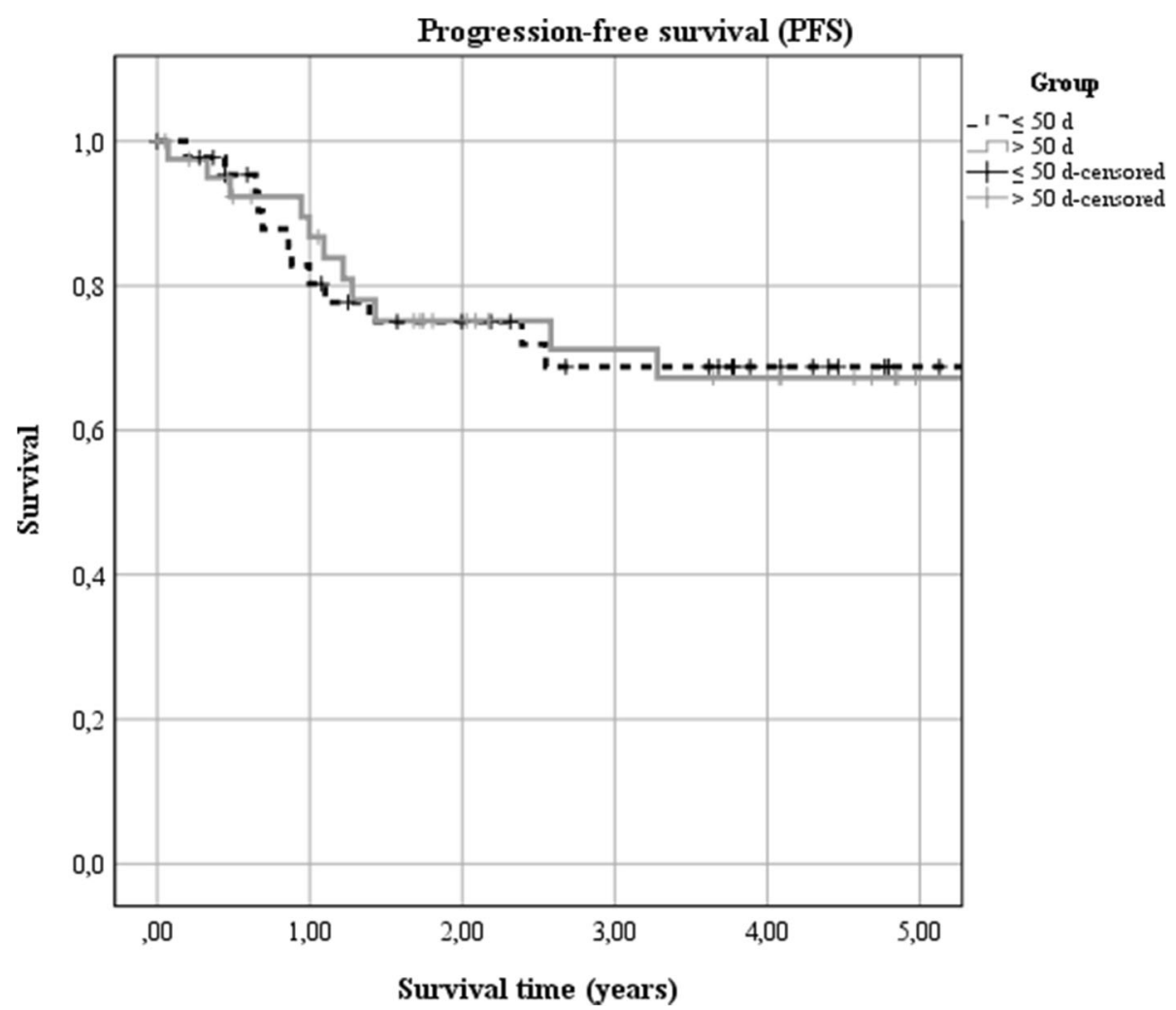

Fig. 2 Association of time span from surgery to adjuvant therapy with progression free survival. Kaplan-Meier estimates of overall survival according to the implementation of adjuvant therapy within $(<55 d)$ and later than $55 d(\geq 55 d)$ after surgery $\left(X^{2}{ }_{(1)}=2.32, p=0.128\right)$

time between surgical tumor removal and initiation of adjuvant therapy. Thus, adjuvant therapy should not be omitted, also in case of a delay.

In general, adjuvant therapy is recommended to be applied within a short time frame following surgery to avoid the growth of residual malignant cells and to maximize the effect of radiation therapy [26-28]. For head and neck cancer, Chen et al. recommend the implementation of adjuvant therapy within six weeks after surgery, although head and neck cancer of unknown primary was not explicitly reviewed [20]. In contrast to our results Grau et al. demonstrated in a Danish multicenter study that a prolonged overall treatment, i.e. at the cutoff of $50 \mathrm{~d}$, significantly impaired neck control and regional tumor control but not survival. However, their analysis did not distinguish between HPV positive and negative CUPs and also included $20 \%$ cases with the appearance of a primary tumor during the study period [1, 29]. Apart from that there is no data regarding the oncologic outcome for prolonged adjuvant radiation therapy/ chemoradiation therapy after primary surgery in CUPpatients.

However, the effect of time to radiation therapy after surgery has already been studied for head and neck cancer in general. In their cohort study including 25.216 patients, Harris et al. reported that a rather shorter interval from the date of surgery to the start of radiation therapy within 42 days was associated with an improved survival for head and neck squamous cell carcinoma. The early treatment group in the presented study started with adjuvant therapy following surgery on average after $41.69 \mathrm{~d}$. Interestingly, treatments that were carried out entirely at an academic center were associated with longer delays to start radiation ( $>42$ days) but still improved survival regardless of the HPV-status (HR 1.06; 95\% CI, 1.01-1.12). This is in line with our observation for advanced staged head and neck CUP-Syndromes treated at our academic center, that delayed adjuvant therapy did not significantly compromise the overall survival rate [30].

The oncological outcome in general for the patients in this study with a 5-year overall survival rate of $71 \%$, a 5 year disease-specific survival rate of $86 \%$ and a 5 -year progression-free survival rate of $72 \%$ is comparable or even superior to available literature and demonstrates the improvement of the overall survival in the treatment of advanced-stage CUPs. The aforementioned study by Grau et al. which reported a 5-year overall survival rate of $37 \%$ resulting from unimodal treatment with radiation therapy during the period of 1975 to 1995 [1] while more recent 


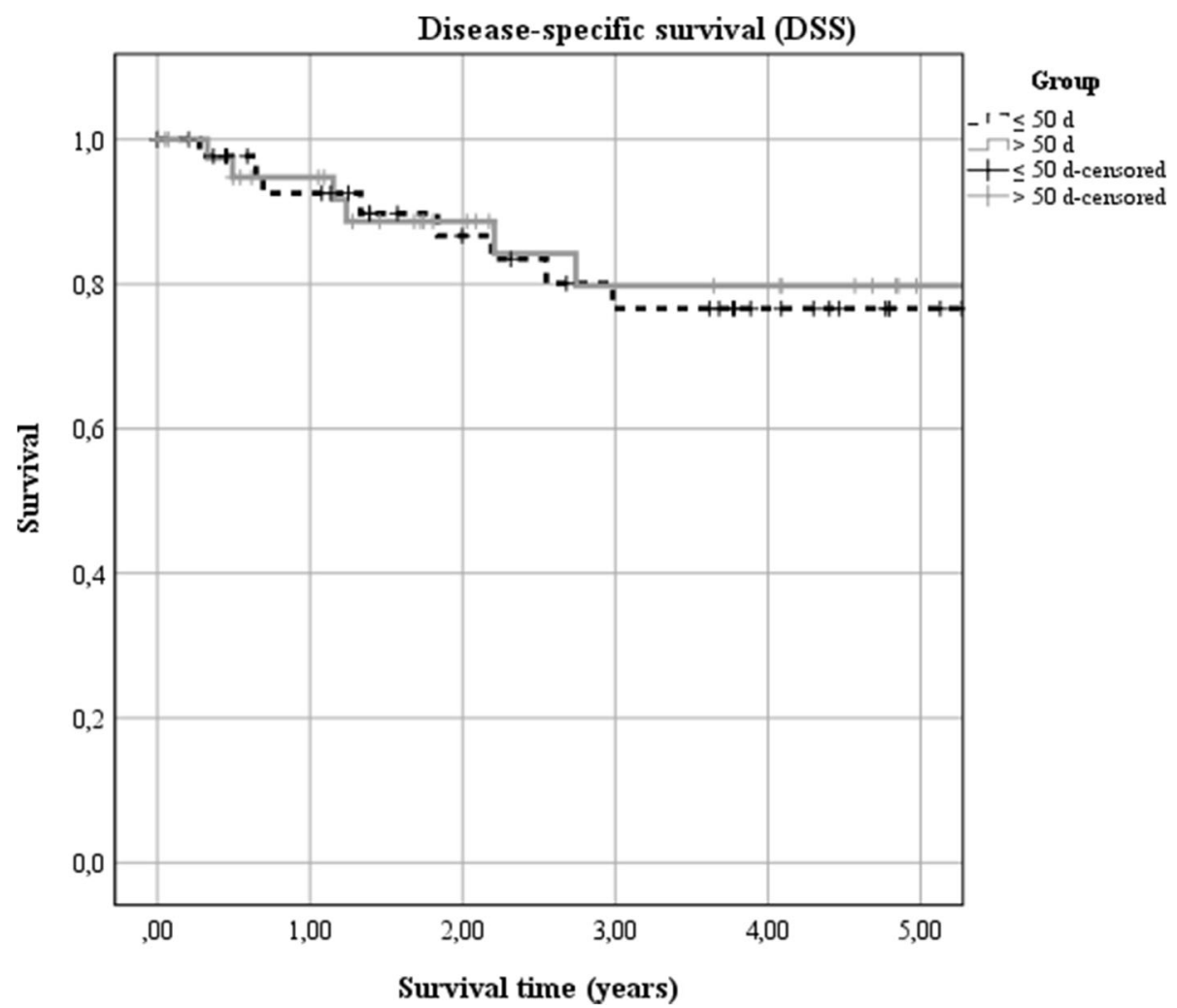

Fig. 3 Association of time span from surgery to adjuvant therapy with disease specific survival. Kaplan-Meier estimates of overall survival according to the implementation of adjuvant therapy within $(<55 d)$ and later than $55 d(\geq 50 d)$ after surgery $\left(X^{2}{ }_{(1)}=0.29, p=0.589\right)$

studies investigating multimodal treatment report 5-year overall survival rates ranging from $40,9 \%$ to $78,9 \%$ [3135]. Especially the low rate of regional recurrences of only $8.5 \%$ highlights the high efficacy of surgery followed by chemoradiation therapy. However, $18.6 \%$ of patients developed distant metastases, which indicates the need for improved systemic therapy. A possible future direction might be the integration of immunotherapy, which is efficient in recurrent/metastatic HNSCC $[36,37]$ and probably also in addition to induction chemotherapy for HNSCC [38] but seems to require adequate patient selection when administered concomitant to chemoradiation therapy of HNSCC [39].

The foremost limitation of this study is due to the inevitable bias of the retrospective character of the analysis. However, the study is based on a homogeneous cohort of patients with well comparable groups revealing similar characteristics. Nevertheless, the number of patients considered is comparable to available literature on this topic $[6-8,40]$. Regarding the included patients, our results refer to advanced-stage head and neck CUPs that are HPV-negative and may not be readily generalizable to early-stage disease and/or HPV-positive CUPs. In addition, it must be mentioned that the administration of 70 Gy to the nasopharynx and 50 Gy to the contralateral tonsil, tongue base and hypopharynx is the traditionally established treatment regimen in our center. Since no relevant nasopharyngeal- or contralateral oro-/hypopharyngeal mucosal associated toxicities have occurred in recent decades, this treatment regimen was not changed during the period of the current analysis (2007-2020).

Of note, this study did not intend to define a definitive threshold time between surgery and the implementation of adjuvant therapy as this was beyond the scope of this study. This crucial topic warrants further investigations preferably multicenter to increase the number of included patients.

The presented results indicate that in head and neck-CUP patients a time span of more than 55 days from surgery to the implementation of adjuvant therapy does not significantly affect the 5-year overall survival rate, although there may be a benefit for those patients which received adjuvant therapy within 55 d. In conclusion, patients with advanced staged CUP-Syndrome may also benefit from delayed adjuvant therapy and therefore it should not be withheld from patients with a prolonged time in between surgery and adjuvant therapy. 


\section{Conclusion}

The results of this study demonstrate that delayed adjuvant therapy in head and neck-CUP-syndrome more than 55 days after surgery did not significantly impair the 5-year overall survival rate, the 5-year diseasespecific survival rate and the 5-year progression-free survival rate. Nevertheless, oncologic outcome tends to be superior for early adjuvant therapy. Further studies with larger patient cohorts are needed to evaluate a definitive threshold time frame.

\section{Acknowledgements}

Dr. Magdalene Ortmann, Ortmann Statistik (https://ortmann-statistik.de).

\begin{abstract}
Authors' contributions
Matthias Balk: conception and design, acquisition of data, analysis and interpretation of data, wrote the main manuscript, final approval of the version to be published. Robin Rupp: acquisition of data, critical revision of the article. Konstantin Mantsopoulos: critical revision of the article. Moritz Allner: critical revision of the article. Philipp Grundtner: acquisition of data, analysis and interpretation of data, critical revision of the article. Sarina Müller: critical revision of the article. Maximilian Traxdorf: critical revision of the article. Markus Eckstein: critical revision of the article. Stefan Speer: critical revision of the article. Sabine Semrau: critical revision of the article. Rainer Fietkau: critical revision of the article, final approval of the version to be published. Heinrich Iro: critical revision of the article, final approval of the version to be published. Markus Hecht: acquisition of data, critical revision of the article, final approval of the version to be published. Antoniu-Oreste Gostian: conception and design, acquisition of data, analysis and interpretation of data, drafting and critical revision of the article, final approval of the version to be published. The author(s) read and approved the final manuscript.
\end{abstract}

\section{Funding}

Not applicable. Open Access funding enabled and organized by Projekt DEAL.

\section{Availability of data and materials}

The datasets used and/or analysed during the current study are available from the corresponding author on reasonable request.

\section{Declarations}

\section{Ethics approval and consent to participate}

The Ethics Committee of the University of Erlangen-Nuremberg has approved the presented work (approval number 428_20 Bc).

The need for informed consent was waived off by the Ethics Committee of the Friedrich-Alexander University of Erlangen-Nuremberg, because this was a retrospective study.

This study was carried out according to the Declaration of Helsinki (in accordance with the relevant guidelines and regulations).

\section{Consent for publication}

Not applicable.

\section{Competing interests}

The authors declare that they have no competing interests.

\section{Author details}

${ }^{1}$ Department of Otolaryngology, Head \& Neck Surgery, University Hospital Erlangen, Friedrich-Alexander University Erlangen-Nuremberg, 91054 Erlangen, Germany. ${ }^{2}$ Department of Pathology, University Hospital Erlangen, Friedrich-Alexander University Erlangen-Nuremberg, Erlangen, Germany. ${ }^{3}$ Department of Radiation Oncology, University Hospital Erlangen, Friedrich-Alexander University Erlangen-Nuremberg, Erlangen, Germany.
Received: 17 May 2021 Accepted: 12 October 2021

Published online: 18 November 2021

\section{References}

1. Grau C, Johansen LV, Jakobsen J, Geertsen P, Andersen E, Jensen BB. Cervical lymph node metastases from unknown primary tumours. Results from a national survey by the Danish Society for Head and Neck Oncology. Radiother Oncol. 2000;55(2):121-9. https://doi.org/10.1016/S0167-814 0(00)00172-9.

2. Motz K, Qualliotine JR, Rettig E, Richmon JD, Eisele DW, Fakhry C. Changes in unknown primary squamous cell carcinoma of the head and neck at initial presentation in the era of human papillomavirus. Jama Otolaryngology-Head \& Neck Surgery. 2016;142(3):223-8. https://doi.org/1 0.1001/jamaoto.2015.3228.

3. Galloway TJ, Ridge JA. Management of Squamous Cancer Metastatic to cervical nodes with an unknown primary site. J Clin Oncol. 2015;33(29): 3328-37. https://doi.org/10.1200/JCO.2015.61.0063.

4. Strojan P, Ferlito A, Medina JE, Woolgar JA, Rinaldo A, Robbins KT, et al. Contemporary management of lymph node metastases from an unknown primary to the neck: I. a review of diagnostic approaches. Head Neck. 2013; 35(1):123-32. https://doi.org/10.1002/hed.21898.

5. Jensen DH, Hedback N, Specht L, Høgdall E, Andersen E, Therkildsen MH, et al. Human papillomavirus in head and neck squamous cell carcinoma of unknown primary is a common event and a strong predictor of survival. PLoS One. 2014;9(11):e110456. https://doi.org/10.1371/journal.pone.0110456.

6. Keller LM, Galloway TJ, Holdbrook T, Ruth K, Yang D, Dubyk C, et al. p16 status, pathologic and clinical characteristics, biomolecular signature, and long-term outcomes in head and neck squamous cell carcinomas of unknown primary. Head Neck. 2014;36(12):1677-84. https://doi.org/10.1002/ hed.23514.

7. Kobayashi K, Saito Y, Omura G, Ando M, Sakamoto T, Yamasoba T, et al. Clinical features of human papilloma virus-related head and neck squamous cell carcinoma of an unknown primary site. ORL J Otorhinolaryngol Relat Spec. 2014;76(3):137-46. https://doi.org/10.1159/000363190.

8. Axelsson L, Nyman J, Haugen-Cange $H_{\text {, Bove } M}$, Johansson L, de Lara S, et al. Prognostic factors for head and neck cancer of unknown primary including the impact of human papilloma virus infection. J Otolaryngol Head Neck Surg. 2017;46(1):45. https://doi.org/10.1186/s40463-017-0223-1.

9. Jakobsen J, Aschenfeldt P, Johansen J, Jørgensen K. Lymph node metastases in the neck from unknown primary tumour. Acta Oncol. 1992; 31(6):653-5. https://doi.org/10.3109/02841869209083848.

10. Jose B, Bosch A, Caldwell WL, Frias Z. Metastasis to neck from unknown primary tumor. Acta Radiol Oncol Radiat Phys Biol. 1979;18(3):161-70. https://doi.org/10.3109/02841867909128203.

11. Yalin Y, Pingzhang T, Smith Gl, Ilankovan V. Management and outcome of cervical lymph node metastases of unknown primary sites: a retrospective study. Br J Oral Maxillofac Surg. 2002;40(6):484-7. https://doi.org/10.1016/ S0266435602002449.

12. Hauswald $H$, et al. Surgery with complete resection improves survival in radiooncologically treated patients with cervical lymph node metastases from cancer of unknown primary. Strahlenther Onkol. 2008;184(3):150-6. https://doi.org/10.1007/s00066-008-1765-y.

13. Balaker AE, Abemayor E, Elashoff D, St. John MA. Cancer of unknown primary: does treatment modality make a difference? Laryngoscope. 2012; 122(6):1279-82. https://doi.org/10.1002/lary.22424.

14. Maghami E, Ismaila N, Alvarez A, Chernock R, Duvvuri U, Geiger J, et al. Diagnosis and Management of Squamous Cell Carcinoma of unknown primary in the head and neck: ASCO guideline. J Clin Oncol. 2020;38(22): 2570-96. https://doi.org/10.1200/JCO.20.00275.

15. Pfister DG, Spencer S, Adelstein D, Adkins D, Anzai Y, Brizel DM, et al. Head and neck cancers, version 2.2020, NCCN clinical practice guidelines in oncology. J Natl Compr Cancer Netw. 2020;18(7):873-98. https://doi.org/10. 6004/jnccn.2020.0031.

16. Kirschner MJ, Fietkau R, Waldfahrer F, Iro H, Sauer R. Therapy pf cervical lymph node metastases of unknown primary tumor. Strahlenther Onkol. 1997:173(7):362-8. https://doi.org/10.1007/BF03038239.

17. de Braud F, Heilbrun LK, Ahmed K, Sakr W, Ensley JF, Kish JA, et al. Metastatic squamous cell carcinoma of an unknown primary localized to the neck. Advantages of an aggressive treatment. Cancer. 1989;64(2):510-5. https://doi.org/10.1002/1097-0142(19890715)64:2<510::AID-CNCR282064022 5>3.0.CO;2-2. 
18. Haussmann J, Tamaskovics B, Bölke E, Djiepmo-Njanang FJ, Kammers K, Corradini $\mathrm{S}$, et al. Addition of chemotherapy to hyperfractionated radiotherapy in advanced head and neck cancer-a meta-analysis. Strahlenther Onkol. 2019;195(12):1041-9. https://doi.org/10.1007/s00066-01901511-z.

19. Wirtz MM, Temming S, Kocher M, Kunze S, Semrau R. Low risk of contralateral lymph node recurrence in lateralized head and neck carcinoma after postoperative ipsilateral radiotherapy. Strahlenther Onkol. 2020;196(5):474-84. https://doi.org/10.1007/s00066-019-01556-0.

20. Chen Z, King W, Pearcey R, Kerba M, Mackillop WJ. The relationship between waiting time for radiotherapy and clinical outcomes: a systematic review of the literature. Radiother Oncol. 2008;87(1):3-16. https://doi.org/1 0.1016/.j.radonc.2007.11.016.

21. Robbins KT, Medina JE, Wolfe GT, Levine PA, Sessions RB, Pruet CW. Standardizing neck dissection terminology. Official report of the Academy's Committee for Head and Neck Surgery and oncology. Arch Otolaryngol Head Neck Surg. 1991;117(6):601-5. https://doi.org/10.1001/archotol.1991.01 870180037007.

22. Stein JP, et al. Risk factors for patients with pelvic lymph node metastases following radical cystectomy with en bloc pelvic lymphadenectomy: concept of lymph node density. J Urol. 2003;170(1):35-41. https://doi.org/1 0.1097/01.ju.0000072422.69286.0e.

23. Gil Z, Carlson DL, Boyle JO, Kraus DH, Shah JP, Shaha AR, et al. Lymph node density is a significant predictor of outcome in patients with oral cancer. Cancer. 2009;115(24):5700-10. https://doi.org/10.1002/cncr.24631.

24. Brierley JD, G.M., Wittekind C., TNM Classification of Malignant Tumors. 8th ed.: Hoboken, NJ, USA: Wiley-Blackwell; 2016.

25. Field A. Discovering statistics using SPSS. 2nd ed. London: SAGE; 2005.

26. Chen MM, Roman SA, Yarbrough WG, Burtness BA, Sosa JA, Judson BL. Trends and variations in the use of adjuvant therapy for patients with head and neck cancer. Cancer. 2014;120(21):3353-60. https://doi.org/10.1002/ cncr.28870.

27. Kiyota N, Tahara M, Fujii M. Adjuvant treatment for post-operative head and neck squamous cell carcinoma. Jpn J Clin Oncol. 2015;45(1):2-6. https://doi. org/10.1093/jjco/hyu195.

28. Jensen AR, Nellemann HM, Overgaard J. Tumor progression in waiting time for radiotherapy in head and neck cancer. Radiother Oncol. 2007:84(1):5-10. https://doi.org/10.1016/j.radonc.2007.04.001.

29. Sievert M, Goncalves M, Mueller SK, Hecht M, Pflaum A, Grundtner P, et al. Impact of delayed adjuvant therapy after surgery in p16 positive oropharyngeal cancer: a retrospective analysis. Eur Rev Med Pharmacol Sci. 2020;24(3):1211-8. https://doi.org/10.26355/eurrev_202002_20173.

30. Harris JP, Chen MM, Orosco RK, Sirjani D, Divi V, Hara W. Association of Survival with Shorter Time to radiation therapy after surgery for US patients with head and neck Cancer. JAMA Otolaryngol Head Neck Surg. 2018; 144(4):349-59. https://doi.org/10.1001/jamaoto.2017.3406

31. Aslani M, Sultanem K, Voung T, Hier M, Niazi T, Shenouda G. Metastatic carcinoma to the cervical nodes from an unknown head and neck primary site: is there a need for neck dissection? Head Neck. 2007;29(6):585-90. https://doi.org/10.1002/hed.20581.

32. Rodel RM, et al. Impact of distant metastasis in patients with cervical lymph node metastases from cancer of an unknown primary site. Ann Otol Rhinol Laryngol. 2009;118(9):662-9. https://doi.org/10.1177/000348940911800911.

33. Beldi $D$, et al. Role of radiotherapy in the treatment of cervical lymph node metastases from an unknown primary site: retrospective analysis of 113 patients. Int J Radiat Oncol Biol Phys. 2007;69(4):1051-8. https://doi.org/10.1 016/j.ijrobp.2007.04.039.

34. Wallace A, Richards GM, Harari PM, Kirwan JM, Morris CG, Katakam H, et al. Head and neck squamous cell carcinoma from an unknown primary site. Am J Otolaryngol. 2011;32(4):286-90. https://doi.org/10.1016/j.amjoto.2010. 05.004.

35. Strojan P, Ferlito A, Langendijk JA, Corry J, Woolgar JA, Rinaldo A, et al. Contemporary management of lymph node metastases from an unknown primary to the neck: II. A review of therapeutic options. Head Neck. 2013; 35(2):286-93. https://doi.org/10.1002/hed.21899.

36. Ferris RL, Blumenschein G Jr, Fayette J, Guigay J, Colevas AD, Licitra L, et al. Nivolumab vs investigator's choice in recurrent or metastatic squamous cell carcinoma of the head and neck: 2-year long-term survival update of CheckMate 141 with analyses by tumor PD-L1 expression. Oral Oncol. 2018; 81:45-51. https://doi.org/10.1016/j.oraloncology.2018.04.008.
37. Burtness B, Harrington KJ, Greil R, Soulières D, Tahara M, de Castro G Jr, et al. Pembrolizumab alone or with chemotherapy versus cetuximab with chemotherapy for recurrent or metastatic squamous cell carcinoma of the head and neck (KEYNOTE-048): a randomised, open-label, phase 3 study. Lancet. 2019;394(10212):1915-28. https://doi.org/10.1016/S0140-6736(19)32 591-7.

38. Semrau, S., Gostian A.O., Traxdorf M., Eckstein M., Rutzner S., von der Grün J., Illmer T., Hautmann M., Klautke G., Laban S., Brunner T., Tamaskovics B., Frey B., Zhou J.G., Geppert C.I., Hartmann A., Balermpas P., Budach W., Gaipl U., Iro H., Fietkau R., Hecht M., Implementation of Double Immune Checkpoint Blockade Increases Response Rate to Induction Chemotherapy in Head and Neck Cancer. Cancers (Basel), 2021. 13(8), 13, 8, doi: https://doi.org/10.3390/ cancers13081959.

39. E.E. Cohen, R.L.F., A. Psyrri, R. Haddad, M. Tahara, J. Bourhis, K.J. Harrington, P. M-H. Chang, J-C. Lin, M. Razaq, M.M. Teixeira, J. Lovey, J. Chamois, A. Rueda Dominguez, C. Hu, M. Dvorkin, S. De Beukelaer, D. Pavlov, H. Thurm, N. Lee, 9100 Primary results of the phase III JAVELIN head \& neck 100 trial: Avelumab plus chemoradiotherapy (CRT) followed by avelumab maintenance vs CRT in patients with locally advanced squamous cell carcinoma of the head and neck (LA SCCHN). Annals of Oncology 2020. Volume 31, Supplement 4.

40. Boeker R, Stromberger C, Heiland M, Beck-Broichsitter B, Hofmann VM, Neumann $\mathrm{K}$, et al. Carcinoma of unknown primary and the 8th edition TNM classification for head and neck Cancer. Laryngoscope. 2021;131(9):E253442. https://doi.org/10.1002/lary.29499.

\section{Publisher's Note}

Springer Nature remains neutral with regard to jurisdictional claims in published maps and institutional affiliations.
Ready to submit your research? Choose BMC and benefit from:

- fast, convenient online submission

- thorough peer review by experienced researchers in your field

- rapid publication on acceptance

- support for research data, including large and complex data types

- gold Open Access which fosters wider collaboration and increased citations

- maximum visibility for your research: over $100 \mathrm{M}$ website views per year

At BMC, research is always in progress.

Learn more biomedcentral.com/submissions 